Ciência e Natura, Santa Maria, v. 37 n. 4 set-dez 2015, p. 673-677

Revista do Centro de Ciências Naturais e Exatas - UFSM

ISSN impressa: 0100-8307 ISSN on-line: 2179-460X

\title{
Determinação de sólidos sedimentáveis: um estudo preliminar sobre biomassas residuais de café e ervas-mate comerciais
}

Determination of solid settleable: a preliminary study about waste biomass coffee and commercial mate herbs

\author{
Sérgio Thode Filho ${ }^{1}$, Hudson Jean Bianquini Couto², Siomara Dias da Costa Lemos ${ }^{3}$, Elisa \\ Raquel A. F. Avelino ${ }^{4}$, Monica Regina da Costa Marques ${ }^{5}$
}

\author{
1Professor do Instituto Federal de Educação, Ciência e Tecnologia do Rio de Janeiro - IFRJ, Campus Duque de \\ Caxias, RJ, Laboratório Multidisciplinar de Gerenciamento de Resíduos (LMGR), Rio de Janeiro, Brasil \\ ${ }_{2}^{2}$ Professor do Instituto Federal do Rio de Janeiro - IFRJ, Campus Duque de Caxias - RJ- colaborador do LMGR, Rio \\ de Janeiro, Brasil \\ ${ }^{3}$ Bolsista CAPES da UERJ, Laboratório de Biotecnologia de Plantas (LABPLAN) e Laboratório de Biorremediação e \\ Fitotecnologias (LABIFI), Rio de Janeiro, Brasil \\ ${ }^{4}$ Professora do IBRAG-UERJ, Rio de Janeiro, Brasil \\ 5Professora PPGMA-UERJ, Rio de Janeiro, Brasil
}

\section{Resumo}

Atualmente, o Brasil é o maior produtor mundial de café, sendo responsável por 32,4\% da produção. Além de maior produtor, o Brasil é o segundo maior mercado consumidor, sendo superado pelos Estados Unidos. A borra de café é um resíduo que ainda não possui valor comercial e sendo comumente descartado. Neste mesmo contexto encontra-se o mate ou chimarrão, como são conhecidas as bebidas frias ou quentes, oriundas da infusão feita com folhas e talos secos, picados e tostados de erva-mate Ilex paraguayensis. $O$ presente trabalho objetiva realizar os testes de sólidos sedimentáveis. Desta forma, ressalta-se a importância do impacto ambiental provocado pelo descarte inadequado das biomassas residuais de café e ervas-mate comerciais em corpos hídricos. Para determinação de sólidos sedimentáveis foram seguidas as recomendações da NBR 10561 - Determinação de sólidos sedimentáveis - método do cone de Imhoff. Para realização dos testes, trabalhou-se com as seguintes massas absolutamente secas: 2,5 g, 7,5 g, $15 \mathrm{~g}, 31 \mathrm{~g}, 67 \mathrm{~g}$ e $80 \mathrm{~g}$ das biomassas residuais da borra de café, erva-mate (I. paraguarienses) in natura e tostada. A partir dos experimentos realizados pôde-se concluir preliminarmente que as biomassas residuais de café e ervas-mate comerciais são sedimentáveis e potenciais poluidores e contaminantes de corpo hídricos, e, por isso, demandam atenção e medidas preventivas elou mitigadoras por parte da população, estabelecimentos comerciais e autoridades públicas.

Palavras-chave: biomassa residual, sólidos sedimentáveis, impacto ambiental.

\section{Abstract}

Currently, Brazil is the world's largest coffee producer, accounting for $32.4 \%$ of production. Besides largest producer, Brazil is the second largest consumer market, surpassed by the United States. The coffee grounds is a residue that does not have commercial value and is usually discarded. In the same context is the mate or chimarrão, as they are known for hot or cold drinks, derived from the infusion of dried leaves and stalks, chopped and roasted yerba mate Ilex paraguayensis. This paper aims to make the settling solids tests. Thus, it emphasizes importance of environmental impact caused by improper disposal of waste biomass of coffee and commercial mate herbs in water bodies receiver. To determine the settling solids were followed the recommendations of NBR 10561 Determination of settling solids - Imhoff cone method. To perform the test, we worked with the following absolutely dry pasta: $2.5 \mathrm{~g}$, $7.5 \mathrm{~g}, 15 \mathrm{~g}, 31 \mathrm{~g}, 67 \mathrm{~g}$ and $80 \mathrm{~g}$ of waste biomass from coffee grounds, mate (I. paraguarienses) fresh and toasted. From the experiments it can be concluded preliminarily that waste coffee biomass and commercial mate herbs are sedimentary and potential polluters and contaminants of the water bodies receiver and therefore demand attention and preventive and/or mitigation measures by the population, companies and public authorities

Keywords: residual biomass, settleable solids, environment impact. 


\section{Introdução}

$\mathrm{S}$ egundo a International Coffee Organization (ICO), no ano de 2011, foram produzidas 7 milhões de toneladas de grãos de café. Atualmente, o Brasil é o maior produtor mundial de café, sendo responsável por $32,4 \%$ da produção. Além de maior produtor, o Brasil é o segundo maior mercado consumidor, sendo superado pelos Estados Unidos (ICO, 2012). Neste sentido, estes resultados devem aumentar, pois o aumento da demanda do mercado brasileiro foi de 5,34 \% de 2011 para 2012 (ABIC, 2012).

A bebida do café é preparada com água quente e, quando se trata de café espresso, utilizase pressão (entre 10 e 20 bar) para favorecer a extração de compostos que contribuem para uma maior qualidade sensorial da bebida. O material insolúvel resultante da extração da bebida do café a quente é chamado borra de café. A borra é um resíduo que ainda não possui valor comercial e comumente descartado. Nos últimos anos, a necessidade de mitigação de resíduos e proteção ambiental tem estimulado pesquisas que visam o uso da borra como fonte de novos compostos de interesse industrial. Para cada $1 \mathrm{~kg}$ de café solúvel, gera-se $2 \mathrm{~kg}$ de borra úmida, com cerca de $75 \%$ a $80 \%$ de umidade (ZUORRO e LAVECCHIA, 2012).

Neste mesmo contexto encontra-se o mate ou chimarrão, como são conhecidas as bebidas frias ou quentes, oriundas da infusão de folhas secas e moídas da erva-mate (I. paraguayensis), que apresenta características sensoriais específicas, sendo que, o seu consumo é, na maior parte, em forma de chimarrão, o qual é característico da região Sul do Brasil onde é um importante produto no contexto econômico e cultural. $\mathrm{O}$ Brasil é o segundo maior produtor de erva-mate, produzindo anualmente 270 mil toneladas e, em média, 30\% da população da América do Sul ingere mais de 1 litro/dia desta bebida. Da mesma forma que com o café, o material insolúvel resultante da extração da bebida da erva-mate (mate ou chimarrão) é um resíduo que ainda não possui valor comercial e comumente descartado (NEUMANN, 1999; BRAGHINI et al., 2014).

As biomassas residuais de café e erva-mate geradas em cafeterias, restaurantes, residências, bares e entre outros não possuem registros devido à dificuldade de quantificar esse tipo de resíduo em diferentes locais (FREITAS, 2000; VEGRO e CARVALHO, 2006; RAMALAKSHMI et al., 2009; PANUSA et al., 2013). Ao longo dos últimos anos muitos esforços têm sido feitos para a valorização dos resíduos e coprodutos agroindustriais, através de processos que transformam estes rejeitos em novos produtos com alto valor agregado (MAKRIS et al., 2007). O presente trabalho objetiva realizar os testes de sólidos sedimentáveis. Desta forma, ressalta-se a importância do impacto ambiental provocado pelo descarte inadequado das biomassas residuais de café e ervas-mate comerciais em corpos hídricos.

\section{Metodologia}

Para iniciar os testes, procedeu-se a coleta das biomassas residuais, borra de café, erva-mate (I. paraguarienses) in natura (chimarrão) $e$ erva-mate (I. paraguarienses) tostada (mate). A amostra das biomassas foram coletadas conforme as condições citadas na NBR 10007 (ABNT, 2004). Posteriormente os materiais foram levados para o Laboratório Multidisciplinar de Gerenciamento de Resíduos (LMGR) do IFRJ-CDUC, onde foram armazenados em geladeira com temperatura regulada a $6 \pm 4^{\circ} \mathrm{C}$ para posterior processamento. Após 7 dias, as amostras foram então desgrumadas e secas até praticamente $0 \%$ de umidade em uma estufa regulada a $80 \pm 5^{\circ} \mathrm{C}$. Com isso, obteve-se uma massa de material a.s. (absolutamente seco). Para determinação de sólidos sedimentáveis foram seguidas as recomendações da NBR 10561 - Determinação de sólidos sedimentáveis - método do cone de Imhoff (ABNT, 1988). Para realização dos testes, trabalhou-se com as seguintes massas a.s.: $2,5 \mathrm{~g}$, $7,5 \mathrm{~g}, 15 \mathrm{~g}, 31 \mathrm{~g}, 67 \mathrm{~g}$ e $80 \mathrm{~g}$ das biomassas residuais da borra de café, erva-mate (I. paraguarienses) in natura e tostada. Os experimentos foram realizados em triplicata. A 
avaliação estatística de regressão linear foi realizada segundo Bussab e Morettin (2010) e objetivou avaliar a proporcionalidade do aumento/redução de sólidos sedimentáveis em relação às diferentes massas a.s. de biomassas residuais de café e ervas-mate estudadas.

\section{Resultado e Discussão}

A partir dos diferentes testes de sólidos sedimentáveis, verificou-se, já no início destes, o quanto das biomassas adicionadas se manteria em suspensão ou depositaria pela ação da gravidade. Assim, é possível constatar-se que, de forma análoga a esta experimentação, estas biomassas residuais quando lançadas em corpo hídrico, apresentam além do volume de sedimentáveis, material em suspensão na coluna d'água e uma fase sobrenadante.

As massas utilizadas na experimentação da borra de café foram satisfatórias para demonstrar o seu comportamento crescente, conforme a figura 1a. O gráfico foi expresso pela função polinomial do segundo grau, em um nível satisfatório de confiança, apresentando o $\mathrm{R}^{2}$ igual a 0,9885 . Verifica-se que a variável dependente sedimentáveis em $\mathrm{mL} / \mathrm{L}$ apresenta variação em função da massa da borra de café, de acordo com a função apresentada, para um domínio trabalhado entre $2,5 \mathrm{~g}$ e $80 \mathrm{~g}$. De acordo com a figura 1, apenas 2,5 $\mathrm{g}$ de massa da borra, gerou 9 $\mathrm{mL} / \mathrm{L}$ em volume.

Da mesma forma que no teste da borra de café, as massas utilizadas no teste de resíduo de erva-mate in natura foram suficientes para demonstrar o seu comportamento linear e crescente, conforme a figura $1 \mathrm{~b}$. O gráfico foi expresso pela função linear, do primeiro grau, em um nível satisfatório de confiança, apresentando o $\mathrm{R}^{2}$ igual a 0,9941 . Verifica-se que a variável dependente sedimentáveis em $\mathrm{mL} / \mathrm{L}$ apresenta variação em função da massa da erva mate (I. paraguarienses), de acordo com a função apresentada, para um domínio trabalhado entre $2,5 \mathrm{~g}$ e $80 \mathrm{~g}$. De acordo com a figura $1 \mathrm{~b}$, apenas 2,5 g de massa residual de erva-mate in natura, gerou $15 \mathrm{~mL} / \mathrm{L}$ em volume.

No teste de resíduo de erva-mate tostada, as massas utilizadas também foram suficientes para demonstrar o seu comportamento linear e crescente, conforme a figura 1c. O gráfico foi expresso pela função linear, do primeiro grau, em um nível satisfatório de confiança, apresentando o $\mathrm{R}^{2}$ igual a 0,9625 . Verifica-se que a variável dependente sedimentáveis em $\mathrm{mL} / \mathrm{L}$ apresenta variação em função da massa da erva mate, de acordo com a função apresentada, para um domínio trabalhado entre $2,5 \mathrm{~g}$ e $80 \mathrm{~g}$. De acordo com a figura 1c, apenas $2,5 \mathrm{~g}$ de ervamate tostada, gerou $32 \mathrm{~mL} / \mathrm{L}$ em volume.

O limite de materiais sedimentáveis impostos pela Resolução 430/11 do CONAMA para lançamento de efluente direto em corpos hídricos receptores é de $1 \mathrm{~mL} / \mathrm{L}$ em teste de 1 hora em cone Imhoff (BRASIL, 2011). Assim, verifica-se que a borra de café, bem como as ervas-mates (in natura e tostada) são resíduos que não se deve descartar diretamente em efluente ou corpo hídrico receptor, pois são biomassas residuais utilizadas em grande escala pela população e geram um volume de material sedimentável bastante expressivo.

Adicionalmente, Zarrelli et al. (2014) ressaltaram a relevância da cafeína como agente poluidor e genotóxico. A cafeína é ubíqua em águas de superfície e subterrâneas e que tem sido proposto como um marcador de pressão antropogênica ao ambiente. Estudos detectaram a presença o material nos EUA (em 72 pontos de águas superficiais), Canadá e Barcelona (águas subterrâneas).

O efluente receptor de cafeína apresenta alto teor de matéria orgânica, sólidos em suspensão, pH ácido e altas taxas de nutrientes. Estudos mostram que esse tipo de resíduo pode ser perigoso para a saúde humana se despejado em locais inapropriados como diretamente nos leitos dos rios ou próximos a residências, os sintomas encontrados são de tontura, irritação nos olhos e na pele, dores estomacais, náuseas e problemas respiratórios (HADDIS; DEVI, 2008).

De acordo com Lima e Farah (2013), a ervamate concentra menor quantidade de cafeína $(0,09 \mathrm{mg} / \mathrm{mL})$, em comparação com o café $(0,52$ $\mathrm{mg} / \mathrm{mL})$. Não há dados quantitativos destes resíduos em efluentes e/ou corpos hídricos, entretanto, pode-se concluir que o café é mais relevante que a erva-mate considerando-se isoladamente o perfil poluidor/contaminante da cafeína. 

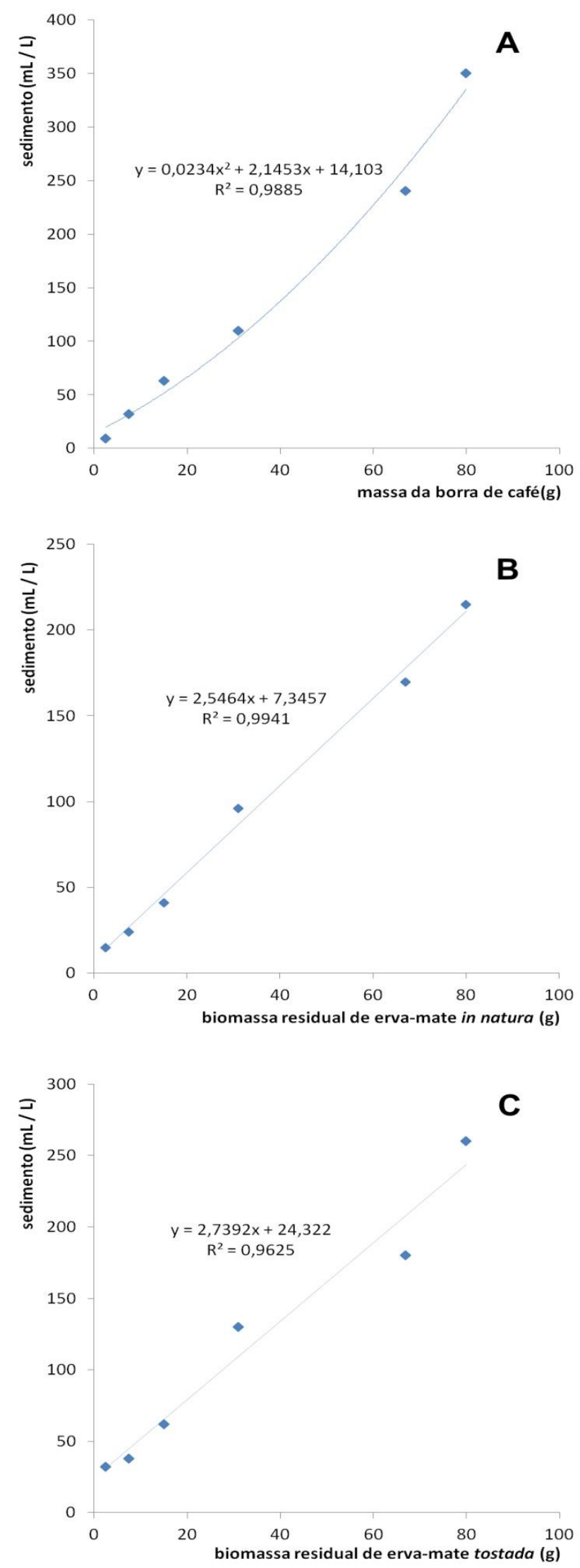

Figura 1. Proporcionalidade do aumento de sólidos sedimentáveis em relação às diferentes massas absolutamente secas de biomassas residuais de café (a) e ervas-mate in natura (b) e tostadas (c).

\section{Conclusão}

A partir dos experimentos realizados pôde-se concluir preliminarmente que as biomassas residuais de café e ervas-mate comerciais são sedimentáveis e potenciais poluidores e contaminantes de corpos hídricos, e, por isso, demandam atenção e medidas preventivas e/ou mitigadoras por parte da população, estabelecimentos comerciais e autoridades públicas.

\section{Referências}

Associação Brasileira de Normas Técnicas (ABNT). (2004). NBR 10007: Amostragem de resíduo - Procedimento. Rio de Janeiro.

Associação Brasileira de Normas Técnicas (ABNT). (1988). NBR 10561: Determinação de resíduo sedimentável - método do cone de Imhoff. Rio de Janeiro.

Associação Brasileira da indústria do café. ABIC. (2014). Disponível em: <www.abic.com.br>. Acesso em: 5 maio de 2014.

Brasil. Resolução oㅡ 430 de 13 de maio de 2011. (2011). Dispõe sobre as condições e padrões de lançamentos de efluentes, complementa e altera a Resolução no 357 , de 17 de março de 2005, do Conselho Nacional do Meio Ambiente - CONAMA.

Braghini, F.; Carli, C. G.; Bonsaglia, B.; Santos, J. F.; Junior, S.; Oliveira, D.F.; Tramujas, J.; Tonial, I.B. (2014). Composição físico-química de erva-mate, antes e após simulação do chimarrão. Pesquisa Agropecuária Gaúcha, v. 20, ns.1/2, p. 7-15.

Bussab, W. D. O., \& Morettin, P. A. (2010). Estatística básica. Saraiva.

Freitas, S.P.; Monteiro, P.L.; Lago, R.C.A. (2000). Extração do óleo da borra do café solúvel com etanol comercial. I Simpósio de Pesquisa dos cafés do Brasil, Industrialização. Poços de Caldas. p.740-743..

Haddis, A.; Devi, R. (2008). Effect of effluent generated from coffee processing plant on The water bodies and human health in its 
vicinity. Journal of Hazardous Materials, v. 152 , p. 259-262.

Lima, J. P.; Farah, A. (2013). Quantificação de cafeína em bebidas carbonatadas e energéticas consumidas. Nutrire, v. 38, p. 203203.

Markis, D.P.; Boskou, G.; Andricopoulos, N.K. (2007). Polyphenolic content and in vitro antioxidant characteristics of wine industry and other agri-food solid waste extracts. Journal of Food Composition and Analysis. Italy. v.20, p.125-132.

Neumann, R. I. (1999). Anuário Brasileiro da Erva-mate. Anuário Brasileiro da Erva-mate.

Panusa, A.; Petrucci, R.; Marrosu, G.; Lavecchia, R.; Zuorro, A.; (2013) Recovery of Natural Antioxidants from Spent Coffee Grounds. Journal of Agricultural and Food Chemistry. v. 61, p.4162-4168.

Ramalakshmi, K.; Rao, L.J.M.; Takano-Ishikawa, Y.; Goto, M. (2009). Bioactivities of low-grade green coffee and spent coffee in different in vitro model systems. Food Chemistry. India. v.115, p.79-85.

Vegro, C. L. R.; Carvalho, F. C. (2006). Disponibilidade e utilização de resíduos gerados no processamento agroindustrial do café. Inf. Econ., v. 24, p. 9-16.

Zarrelli, Armando et al. (2014). Ecotoxicological evaluation of caffeine and its derivatives from a simulated chlorination step. Science of The Total Environment, v. 470, p. 453-458.

Zuorro, A.; Lavecchia, R. (2012). Spent coffee grounds as a valuable source of phenolic compounds and bioenergy. Journal of Cleaner Production. Roma. In Press. 